University of Nebraska - Lincoln

DigitalCommons@University of Nebraska - Lincoln

Educational Psychology Papers and

Publications

Educational Psychology, Department of

September 1992

\title{
A Conceptual Model for the Expansion of Behavioral Consultation Training
}

Susan M. Sheridan

University of Nebraska-Lincoln, ssheridan2@unl.edu

Diane Salmon

National-Louis University

Thomas R. Kratochwill

University of Wisconsin-Madison

Pamela J. Carrington Rotto

University of Wisconsin-Madison

Follow this and additional works at: https://digitalcommons.unl.edu/edpsychpapers

Part of the Educational Psychology Commons

Sheridan, Susan M.; Salmon, Diane; Kratochwill, Thomas R.; and Carrington Rotto, Pamela J., "A Conceptual Model for the Expansion of Behavioral Consultation Training" (1992). Educational Psychology Papers and Publications. 27.

https://digitalcommons.unl.edu/edpsychpapers/27

This Article is brought to you for free and open access by the Educational Psychology, Department of at DigitalCommons@University of Nebraska - Lincoln. It has been accepted for inclusion in Educational Psychology Papers and Publications by an authorized administrator of DigitalCommons@University of Nebraska - Lincoln. 


\title{
A Conceptual Model for the Expansion of Behavioral Consultation Training
}

\author{
Susan M. Sheridan \\ University of Utah \\ Diane Salmon \\ National-Louis University \\ Thomas R. Kratochwill and \\ Pamela J. Carrington Rotto \\ University of Wisconsin-Madison
}

In this article, a general model and specific program that expand traditional behavioral consultation training are presented. The training program involves five interrelated components: (a) procedural and content skills, (b) role and relationship considerations, (c) entry/systems issues, (d) field-based experience, and (e) peer supervision. As a system, each component is necessary but not sufficient in the development of consulting expertise. Likewise, each component is subsumed by one or more components that encompass this broader framework. A theoretical rationale, model for implementation, and future training and research directions are also presented.

Consultation and other forms of interdisciplinary collaborative problem solving have been espoused by many as the foundations for a range of alternative services designed to enhance general educational experiences (Curtis \& Meyers, 1988; Phillips \& McCullough, 1990; Zins, Curtis, Graden, \& Ponti, 1988). In a generic sense, consultation is defined as an indirect form of service delivery, in which a consultant and consultee work cooperatively to identify, evaluate, and remediate difficulties in a client. Of the several models of consultation (e.g., mental

Requests for reprints should be sent to Susan M. Sheridan, Department of Educational Psychology, 327 Milton Bennion Hall, University of Utah, Salt Lake City, UT 84112. 
health, behavioral, organizational, process, clinical, collaborative), the majority of research has been conducted with behavioral consultation (Alpert \& Yammer, 1983), and there is increasing empirical support for behavioral consultation as an effective model of service delivery in school settings (e.g., Kratochwill, Sheridan, Carrington Rotto, \& Salmon, in press; Pray, Kramer, \& Lindskog, 1986; Sheridan, Kratochwill, \& Elliott, 1990).

In the last 10 years, consultation has gained increased attention among school personnel. For example, practicing school psychologists have reported that consultation generally has been a high priority in their delivery of services (Smith, 1984). However, although many practitioners have received didactic training, very few training programs provide a field practicum or other supervised experience in consultation (Meyers, Wurtz, \& Flanagan, 1981). A similar trend is apparent in other areas of education, including special education, educational administration, and teacher training programs (Idol \& West, 1987). Thus, there is a recognized need in graduate programs to prepare students formally in the principles and procedures of school-based consultation.

A number of important consultant competencies have been identified in the consultation literature. West and Cannon (1988) surveyed 100 "experts" in consultation to identify essential consultation competencies for regular and special educators. Using a Delphi technique, 47 competencies in eight categories were deemed essential to the consultation process. Specifically, skills in five broad areas received the highest ratings from the majority of panel members: (a) interactive communication; (b) equity issues, values, and beliefs; (c) personal characteristics; (d) collaborative problem solving; and (e) evaluation of consultation effectiveness. This study has obvious implications for training, however, the most effective way to operationalize and train these skill areas in the context of behavioral consultation is not known.

\section{COMPETENCY-BASED BEHAVIORAL CONSULTATION TRAINING}

Many of the traditional behavioral consultation training programs have evolved from the early work of Bergan and his associates (Bergan, 1977; Bergan \& Kratochwill, 1990; Bergan \& Tombari, 1975, 1976; Kratochwill \& Bergan, 1978, 1990), and many now use competency-based approaches (Kratochwill, Sheridan, Carrington Rotto, \& Salmon, 1991). Training programs typically teach specific verbalization and procedural skills to the consultant-trainee. Interested readers are referred to 
Kratochwill et al. (1991) for a more thorough discussion of objectives and strategies utilized in standardized competency-based training approaches.

In competency-based behavioral consultation training, the effectiveness of behavioral consultants typically is evaluated in regard to knowledge and verbalization skills associated with predefined interview objectives (Brown, Kratochwill, \& Bergan, 1982; Kratochwill, Van Someren, \& Sheridan, 1989). "Competence" or "mastery" is demonstrated when the trainee exhibits a predetermined amount of discrete verbal behaviors. The actual training of behavioral consultation skills is typically done via conventional formats and standardized procedures. The use of standardized materials is desirable because they provide a structured format for novice interviewers, and enhance integrity in meeting the goals and objectives of behavioral consultation.

Empirical support now exists for standardized competency-based approaches that focus on specific verbalization and procedural skills (T. K. Anderson, Kratochwill, \& Bergan, 1986; Kratochwill et al., 1989; Kratochwill et al., in press), however, there is a need to continually develop broadened conceptualizations of behavioral consultation training. Consultant competence in specific verbalizations provides a necessary and essential foundation for the practice of behavioral consultation. However, these verbalization skills are not sufficient to ensure optimal consultant-consultee relations, nor do they address important considerations regarding the situation or context within which consultation occurs. There are many factors beyond mastery of basic consultant verbalization skills that impact the success of the problem-solving process. Behavioral consultation is viewed as a dynamic process between two persons, and every transaction that may transpire cannot be predetermined. For this reason, as the consultant-trainee becomes increasingly adept at applying the rudimentary steps of problem solving, it is critical that his or her skills are expanded with a broader response repertoire. Therefore, addressing additional components such as interpersonal, relationship, and system-related characteristics affords the consultant greater flexibility to respond effectively (Fine, Grantham, \& Wright, 1979).

In this article, an expanded behavioral consultation training format is presented. The general goals of the expanded model include training in basic consultation verbalization skills, awareness of intra- and interpersonal role and relationship issues, and recognition of systemic, contextspecific considerations in practice. The integration and utilization of personal skills and knowledge is made possible in the context of applied consultation and supervision experiences. A conceptual overview and 
rationale for each of the training components is presented, followed by procedural details for the training program. Finally, future training and research directions are discussed.

\section{CONCEPTUAL OVERVIEW FOR TRAINING}

\section{Procedural and Content Knowledge}

To be effective, behavioral consultants require knowledge in at least two broad areas: (a) the process of consultative problem solving (i.e., procedural knowledge of the stages and objectives of behavioral consultation), and (b) the content of consultation interactions (i.e., knowledge regarding assessment, intervention, child development and learning processes, and the particular population with which one is working). A behavioral consultation training program should address competencies in both areas.

Basic procedural skills and discrete verbal behaviors provide an essential foundation and structure for the practice of behavioral consultation. Competence in this area provides the inexperienced consultant with the basic "tools" (i.e., the steps) for problem solving. Beyond the benefits of standardization, specific procedural and verbalization skills provide an initial script for eliciting and organizing relevant information.

The consultant's knowledge and expertise regarding child and/or population considerations also are important. A certain degree of knowledge must be within a consultant's repertoire to: (a) assess broad dimensions of a problem accurately; (b) identify potentially important intervening variables; (c) generate and examine case-related hypotheses; (d) identify factors that could impact problem solution; and (e) develop an appropriate, effective intervention. Thus, content knowledge and expertise are prerequisite to effective consultation practice. With these considerations in mind, early goals of training encompass both consultation procedural and verbalization skills, and an adequate knowledge base regarding the content of a case.

\section{The Consultation Relationship}

Basic interpersonal and communication skills are essential at every stage of consultation. These skills are important for developing a positive consultant-consultee relationship, and for movement towards problem management (Cormier \& Cormier, 1985; Egan, 1986; Fine, 1990). A consultant who is highly effective at meeting the procedural objectives of behavioral consultation will minimize his or her effectiveness if 
positive interpersonal skills and understanding are not integrated with technical expertise (Sheridan, 1988).

Although relationship-enhancing and other interpersonal skills are important in behavioral consultation interviews, specific training objectives are in the early stages of development (Carrington Rotto, 1988). Unfortunately, the empirical literature has not provided clear guidelines on the essential aspects of therapeutic relationship issues in indirect service delivery (Morris \& Nicholson, in press). Specific competencies in relation to discrete interpersonal skills (e.g., empathy, open questions, positive validation) are important, however the use of skills must be considered in the context of the particular consultation relationship in which they are manifested. A consultant's use of interpersonal skills is related to his or her interpretation of others' actions and knowledge of the social context of consultation. Thus, consultee variables and the consultation relationship are critical.

Several factors operate concomitantly to impact the consultative relationship. These include congruence among consultation expectancies, role definition, professional and personal reference points, and theoretical orientations. Although many of these are beyond the consultant's direct control, it is imperative that he or she attempts to adopt alternative perspectives to understand how a problem is perceived and experienced by the consultee (Rosenfield, 1985).

\section{Significance of a Systems Focus}

The focus of behavioral consultation training traditionally has been on the identification, analysis, and remediation of client (child) problems. The problem, however, may be more accurately perceived as "lying in the relationship between the child and the . . . social environment" (Witt \& Martens, 1988, p. 213). Indeed, traditional behavioral consultation practice may not fully address the complex interactions and interdependencies among individual, classroom, culture, family, and community on the educational process. What is needed is an understanding of the broader system within which consultation is occurring, including the pervasive and reciprocal relationships between one's behavior, the environment, and significant others.

Central to training in any applied skill area is the awareness that our practice and behaviors do not occur in isolation. A child, teacher, parent, and consultant all exist as part of a larger social context or system. Thus, the principles of ecological-systems theory must be integrated into a total training program (Petrie et al., 1980). There are several advantages to incorporating ecological-systems theory into consultation training programs. First, it theoretically subsumes other theo- 
ries and is not likely to be inconsistent nor incompatible with other theoretical paradigms used by school psychologists (C. Anderson, 1983; Apter \& Conoley, 1984). Second, an ecological perspective views problems as system centered, rather than individual centered. The individual is seen in context, and consultation training focuses on understanding networks of interrelationships among various individuals and their environments (Apter, 1982). When appropriate, the focus may be on the individual, but the consultant continues to consider the individual as part of a system that cannot be understood without reference to that system.

\section{Integration, Application, and Reflective Supervision}

To individualize and maximize one's training experiences, training must be responsive to the developmental issues that face its consumers (i.e., students). Various concerns of consultant-trainees must be considered, including how they perceive their competencies and roles within a given context and possible consultant-consultee incongruity. Especially important is the continuous evolution of the trainees' sense of their status and identity within this professional role. The manner in which consultants continuously assimilate new information and accommodate their existing professional scheme is important in their overall growth and development.

Consultant learning involves not only basic skill competencies, but also the building of a well-organized system of knowledge about consulting. Through experience and reflection on specific experience, novice consultants construct systems of knowledge from which they interpret information within consultation contexts, and plan and evaluate their own consulting actions (Kelly, 1955; Schon, 1987). These systems of knowledge may be conceptualized as personal theories of practice (Argyris \& Schon, 1974; Cantor \& Kihlstrom, 1987; Salmon \& Lehrer, 1989). Once they have established such a personal framework for consultation, consultants then learn to evaluate their behaviors and continue to evolve more complex systems of understanding.

Research on the nature of consultation expertise suggests that consultant-trainees need help in attending to and actively linking various sources of information within consultation contexts (Salmon \& Lehrer, 1989, 1991). Features of a child-client's behavior, a teacherconsultee's actions and beliefs, and a system's functioning are all critical in anticipating and determining consultation outcomes. As novice consultants acquire consultation verbalization skills and client assessment and intervention skills, they must have time to integrate these 
techniques with their knowledge of the various dimensions of the consultation context. Peer supervision is a means of providing such an opportunity. As peer supervisors, the consultation process is viewed from a more distant vantage point. In this way, novice consultants are better able to see information from different sources within the consultation context and to integrate this information within their emerging personal theory of practice. Ultimately, these personal theories should form the basis of a coherent and flexible system of knowledge about consulting (Carver \& Scheier, 1982).

\section{AN INTEGRATED MODEL OF BEHAVIORAL CONSULTATION TRAINING}

An integrated, systemic model of behavioral consultation training is presented in which training is conceptualized as a system with five interrelated components, or phases. As a system, each component is considered necessary but not sufficient in the development of maximal consultation skills. Likewise, each component is subsumed by one or more components that encompass a broader framework. Figure 1 depicts conceptually the training model that includes: (a) procedural and content skills, (b) role and relationship considerations, (c) entry/systems issues, (d) field-based experience, and (e) peer supervision.

The training program is designed to be implemented as a package, with skills in each phase presented and mastered prior to exposure to subsequent phases. Thus, behavioral consultation verbalization skills are taught first to provide a procedural framework from which to operate. Interpersonal and relationship skills are presented next, followed by entry and systems issues. To maximize consultant opportunities to integrate critical aspects of each phase, these first three training experiences occur in clinical analogue settings prior to actual field-based case exposure. Phase IV is the point of application, when trainees are placed in actual school settings and serve as consultants to teachers or parents. Phase $\mathrm{V}$ allows trainees to alter perspectives and view consultation cases from a distant vantage point (i.e., as a peer supervisor). Table 1 presents specific training components, with strategies and a recommended timeline for effectively implementing the program. It should be emphasized that although the phases are presented sequentially, competence in all areas continues to develop as one becomes exposed to and gains experience in various consultation contexts. 


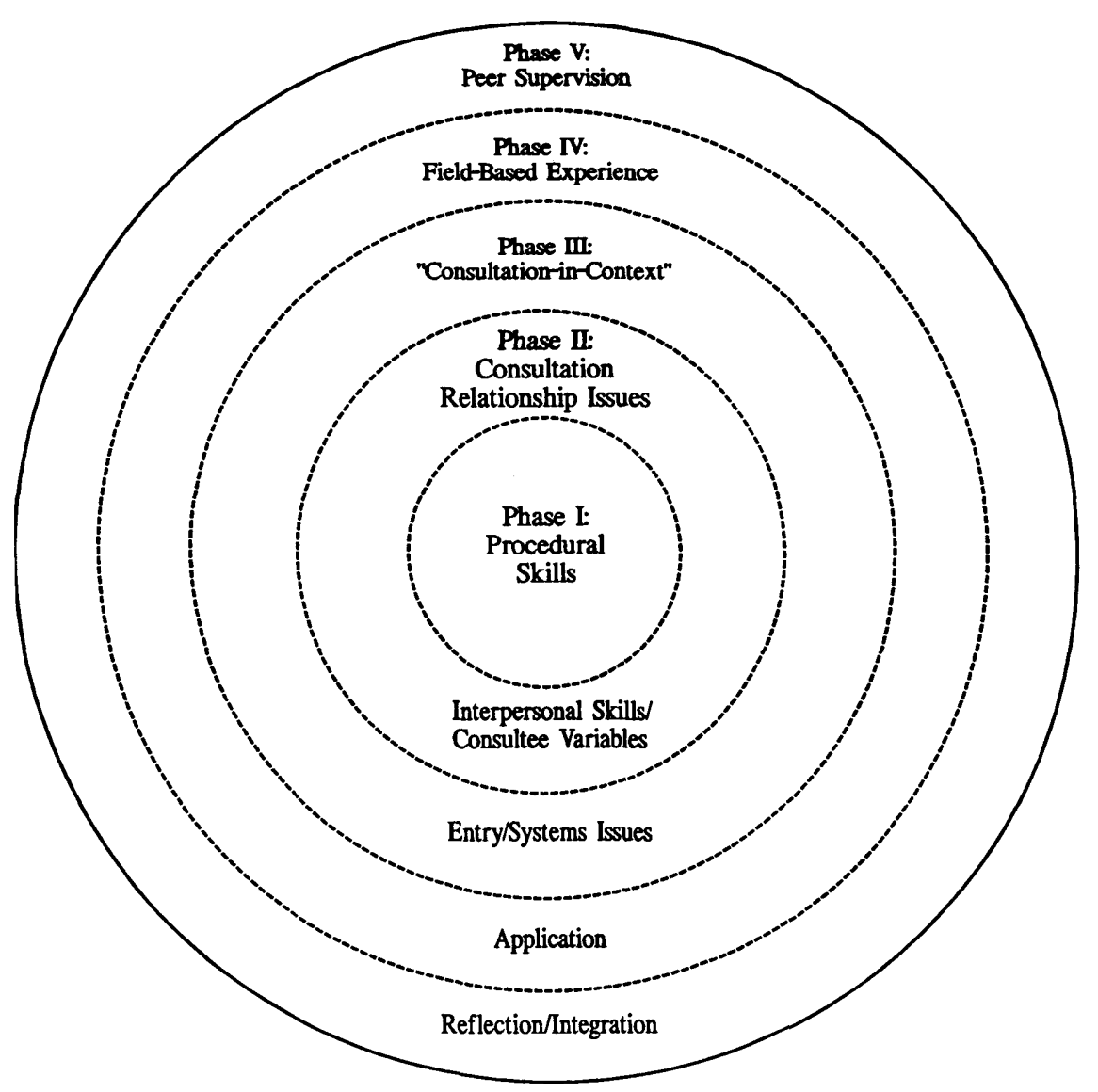

FIGURE 1 Systemic model for training behavioral consultants.

\section{Phase I: Procedural and Content Skills}

Phase I of training addresses consultants' knowledge and skills in relation to the procedures of behavioral consultation, and their utilization within the context of a given case.

Behavioral consultation procedural skills. Behavioral consultation is typically described as occurring in four general stages (i.e., problem identification, problem analysis, treatment implementation, and treatment evaluation). In general, problem identification involves specification of the problem or problems to be targeted in consultation; problem analysis allows one to explore the problem through evaluation of baseline data, identify the variables that might facilitate problem solu- 
I. Procedural and content skills (approximately 3 weeks)

A. Behavioral consultation procedural manual (Week 1)

1. Read entire training manual (see Kratochwill \& Bergan, 1990).

2. Complete self-quizzes.

3. Complete discussion questions in small groups (optional).

B. Behavioral consultation videotape (Week 2)

1. View in small groups.

2. Stop tape and discuss consultant performance.

3. Complete process sheets (i.e., identify specific strengths, weaknesses, overall impressions).

C. Library/training modules (on-going)

1. Include behavioral consultation references.

2. Include references on child, population, and family characteristics.

3. Include references on behavioral assessment, analysis, and evaluation.

D. Analogue role plays (Weeks 2 and 3)

1. Conduct two role plays to include entire behavioral consultation interview process.

2. Audiotape all interviews.

3. Self-monitor performance on objectives checklist.

4. Complete consultation log; establish procedural goals.

5. Receive supervision following each role play.

II. Interpersonal/relationship factors (approximately 2 weeks)

A. Interpersonal/relationship manual (Week 1)

1. Read entire manual.

2. Complete self-report exercises.

3. Discuss in small groups (optional).

B. Half-day workshop

1. Discuss conceptual overview of personal and interpersonal variables.

2. Discuss personal qualities of an effective consultant, selected interpersonal skills for effective consultation, and perspective taking.

3. Explore consultee variables and barriers in consultation; brainstorm methods of overcoming barriers.

4. Demonstrate interpersonal skills within consultation relationship through audiotape, videotape, or live modeling.

5. Engage in consultant self-reflection; set interpersonal goals.

C. Analogue role plays (Week 2)

1. Conduct two role plays to include entire behavioral consultation interview process.

2. Audiotape all interviews.

3. Self-monitor performance on objectives checklist.

4. Complete consultation log; establish procedural and interpersonal goals.

5. Receive supervision following each role play.

III. Entry/systems issues (approximately 2 weeks)

A. Half-day workshop (Week 1)

1. Experts and practitioners present research-based and practical issues of providing consultation services within school contexts.

2. Engage in discussion and dialogue with presenters.

(Continued) 
B. Analogue role plays (Weeks 1 and 2)

1. Conduct two role plays with experienced or student teachers, to include entire behavioral consultation interview process.

2. Audiotape all interviews.

3. Self-monitor performance on objectives checklist.

4. Complete consultation log; establish procedural, interpersonal, and context-related goals.

5. Receive supervision following each role play.

6. Receive verbal feedback from teacher consultee.

IV. Field-based experience (approximately 5 months)

A. Consultation case

1. Complete entire behavioral consultation process with teacher using standardized forms.

2. Audiotape and listen to all interviews.

3. Self-monitor performance on objectives checklist.

4. Reflect on performance and complete consultation log.

5. Establish procedural, interpersonal, and context-related goals for subsequent interviews based on performance in previous interview and supervision.

B. Supervision

1. Receive supervision from advanced peer supervisor following each interview.

2. Reconsider problem situations with supervisor in a systematic fashion.

3. Review logs and determine adequacy of goals.

4. Re-establish procedural and interpersonal goals for subsequent interview, if necessary.

5. Meet with trainers and other consultant-trainees bimonthly to share experiences and gain different perspectives.

V. Peer supervision (approximately 1 year)

A. Consultant supervision

1. Read supervision manual.

2. Review consultant audiotapes following consultation interviews.

3. Complete objectives checklist and review consultants' attainment of procedural, interpersonal, and context-related goals.

4. Generate reflective questions to help consultant consider problem situations and structure supervision session.

5. Help consultant establish procedural, interpersonal, and context-related goals for subsequent interview.

6. Meet with trainers and other peer supervisors bimonthly to share experiences and gain different perspectives.

B. Self-reflection

1. Audiotape and listen to all supervision sessions.

2. Self-monitor performance on supervision checklist.

3. Reflect on performance and complete supervision log.

4. Establish procedural and interpersonal goals for subsequent supervision sessions based on performance in previous session. 
tion, and suggest a plan in an attempt to solve the problem; treatment implementation involves implementation of the plan designed during problem analysis; and treatment evaluation is undertaken to determine the extent of plan effectiveness. These stages are procedurally operationalized through a series of standardized behavioral interviews. ${ }^{1}$

To meet Phase I-training goals, several strategies are used, including a standardized procedural manual (i.e., Kratochwill \& Bergan, 1990), videotaped models, discussions, behavioral rehearsal, self-monitoring, and performance feedback (Kratochwill et al., 1989). Training videotapes of a consultant and teacher engaging in all stages of behavioral consultation enhance modeling opportunities.

Analogue role plays are used to organize and integrate cognitive knowledge into one's behavioral repertoire. In the role plays, students practice the entire process of consultation (Problem Identification, Problem Analysis, and Treatment Evaluation Interviews) with individuals trained to portray a consultee. Standardized training scripts ensure that all consultant-trainees are exposed to the same cases in the analogue situations (Kratochwill et al., 1989). At least two role plays typically are required for each student during Phase I of training. All role-play interview sessions are audiotaped to allow for consultation supervision and self-evaluation. Students review their tapes and conduct self-evaluations by monitoring the degree to which they met the interview objectives. A trainer or peer supervisor (advanced student experienced in behavioral consultation) also provides feedback immediately.

Content knowledge. Along with behavioral consultation procedural knowledge, novice consultants require a strong content knowledge base regarding population characteristics and referral problems. Thus, diverse child characteristics, common referral issues, and handicapping conditions are also addressed during the first phase of training. Various methods can be used to ensure that consultant-trainees have a rudimentary level of knowledge in child and referral issues, including coursework, readings, and standardized quizzes. For example, we have developed a library and specific training modules on various handicapping conditions, assessment considerations, and treatment approaches. Module topics can include emotional disturbance, academic difficulties and learning disabilities, social skills deficits, conduct and behavioral disorders, attention and work completion problems, and effective and

\footnotetext{
${ }^{1}$ Readers interested in more detail regarding specific behavioral objectives of each of the behavioral consultation interviews are referred to Kratochwill and Bergan (1990), and to Kratochwill, Elliott, and Carnington Rotto (1990).
} 
acceptable interventions. A resource library can include texts, papers, and other materials to provide supplemental information.

The basic training procedures in Phase I require approximately 3 weeks to complete. Trainees first complete assigned readings and self-quizzes. Subsequently, they view the training videotape and practice the three interviews of behavioral consultation in analogue role plays. The interviews are audiotaped to allow trainees to self-evaluate their skills and to provide supervisors with concrete performance data. Structured supervision begins at this early stage of learning to identify preliminary competencies and weaknesses, and delineate potential performance goals for future consultation sessions. Given the reciprocal and developmental nature of the training phases, consultants' skills and knowledge bases ideally will continue to increase as they are exposed to subsequent analogue and field-based experiences.

\section{Phase II: Role and Relationship Considerations}

The second phase of the expanded training model emphasizes the uniqueness of each dyadic relationship and the necessity for integrating interpersonal skills into each consultation interaction. The purpose of Phase II is to promote change in consultants' interpersonal awareness, attitudes, and skills. Specifically, training objectives include developing skills in: (a) identifying general issues that influence consultation relationships, (b) recognizing personal attitudes and behaviors that may facilitate or interfere with the establishment of positive consultative relationships, and (c) applying a range of interpersonal skills in consultation sessions.

Phase II training occurs after consultant-trainees demonstrate competence in basic behavioral consultation procedural and verbalization skills. Specific instructional strategies developed for this phase of training include an interpersonal skills manual and a $1 / 2$-day workshop (Carrington Rotto, 1988). We have also developed a training manual to address pertinent interpersonal considerations in the consultative relationship (Carrington Rotto, Sheridan, \& Salmon, 1987). Topical issues addressed in the training manual include: (a) general considerations of relationship issues in consultation, (b) characteristics of effective consultants, (c) development of interpersonal skills, (d) phases of communication, (e) skills for effective consultation, (f) significant episodes in consultation interactions, (g) potential consultant errors, (h) potential barriers, and (i) ethical considerations. The importance of establishing and applying basic interpersonal and communication skills at every stage of behavioral consultation is emphasized.

A 4-hr workshop incorporating group discussion, paper-and-pencil 
tasks, and audio- and videotaped examples of consultation interviews is included in the training model to provide experiential training in relationship and interpersonal variables. The workshop session begins with a conceptual overview of personal and interpersonal variables in consultation (see Figure 2). The consultation interview is presented as the vehicle by which consultant skills interface with consultee characteristics. Discussion focuses on the consultative relationship as a unique and dynamic process, with constantly changing verbal and nonverbal interactions. Although there are common features among consultative relationships (e.g., common roles and procedural similarities), novice consultants are encouraged to acknowledge personal and interpersonal variables within behavioral consultation, and to conceptualize consultation as a relationship. Thus, subsequent components within the workshop focus on personal qualities of an effective consultant, selected interpersonal skills for effective consultation, recognition of consultee variables, potential barriers in the consultation relationship, methods of reducing barriers, perspective taking, self-reflection, and goal setting.

In practice, Phase II requires approximately 2 weeks to complete. In the 1st week, consultant trainees read the interpersonal skills manual and attend a $1 / 2$-day workshop. During the 2 nd week, two role plays with "resistant" or otherwise challenging consultees are scheduled to provide opportunities to practice effective relationship skills in the context of variable consultee characteristics.

\section{Phase III: Entry/Systems Issues in Consultation}

Because systems variables often override individual variables, it is important to understand the realities of the organization in order to understand the individuals within that setting (Conoley \& Conoley, 1982). Thus, to address a broader systems perspective, the training model considers physical-environmental factors of the building and classroom; curricular issues; administrative style; and the social- emo-

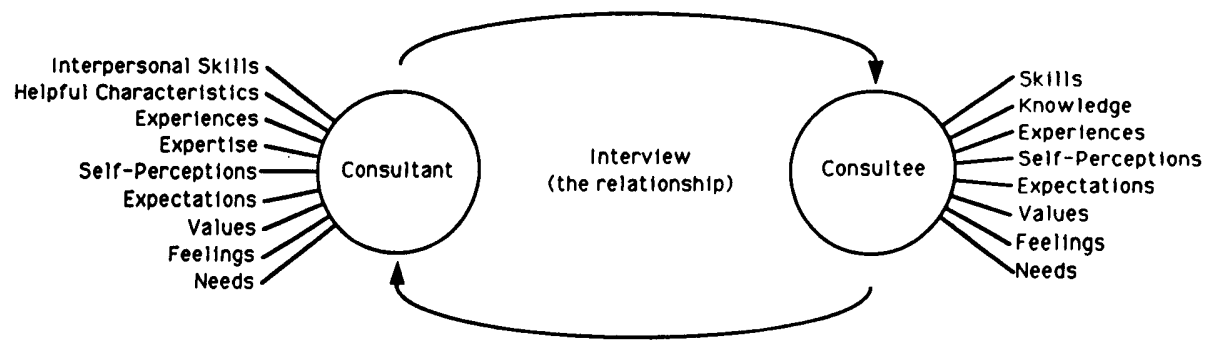

FIGURE 2 Conceptual model of the consultation relationship. 
tional climate, power structure, and communication patterns within the school. Other systems issues incorporated into the training program include entry considerations (e.g., identifying appropriate methods of entering a system, establishing networks and positive work relations), effective use of the system (e.g., maintaining relationships within the system), and potential constraints within the system that may impact consultation attempts.

Our training program uses a $1 / 2$-day workshop format to introduce system-related issues. In this way, the interactions among individual variables (e.g., child, parent, teacher, consultant), physical and ecological factors of the consultation environment (e.g., school and classroom ecologies, curriculum, programmatic considerations), and organizational issues (e.g., power structure, communication patterns, administrative style) are addressed. The workshop includes both didactic (i.e., expert presentations and discussions) and applied (i.e., role plays with experienced or student teachers) components.

The didactic component of the workshop uses expert presenters who review relevant content in a number of areas: (a) academic, curricular, and classroom considerations, including educational programs and classroom-based academic/behavioral strategies; (b) child and family characteristics and relationships between home and school; and (c) larger systemic issues, such as school norms, role considerations, communication patterns, administrative issues, and practical and pragmatic factors in service delivery. Mental health workers, regular or special education classroom teachers, school psychologists, school administrators, and university faculty have been used to disseminate knowledge and expertise in each of these areas.

The applied component of the workshops consist of videotaped interviews with experienced or student teachers. Actual cases are presented to consultant-trainees to encourage the integration and generalization of all prior phases of training in a semi-naturalistic situation. Feedback is provided immediately (i.e., between analogue interviews) by trainers and peer supervisors observing through a one-way mirror. Given that consultees present actual child-related concerns, these role plays provide an excellent transition experience for trainees prior to their first school-based consultation cases.

\section{Phase IV: Field-Based Experience}

Up to this point within the training model, students have been acquiring knowledge and skill relevant to the consultant role. At this juncture, they are provided with an opportunity to apply this knowledge and further refine their skills in the context of a field-based practicum. This 
practicum involves developing at least one consultation relationship with a teacher-consultee in a school setting. The consultants in training use the behavioral consultation process and in addition, they systematically monitor relationship and systems factors that may be influencing the problem-solving process. A series of consultation checklists and journal forms have been used to help novice consultants plan for each of their consultation interviews, monitor the nature of the information gained, and set goals to improve their own efforts as a consultant. Consultants continue to audiotape all their consultation interviews and use these forms to help them reflect on the problem-solving process.

In addition to self-monitoring, novice consultants receive support in applying their new knowledge and skill from a more advanced peer (i.e., peer supervision). During the field-based component, the consultants meet regularly with a peer supervisor. Through peer supervision, the consultants receive feedback on their interviewing techniques and their efforts at building a collaborative relationship with the consultee. Peer supervisors are trained to help consultants think through problem situations in a systematic fashion (see the following Peer Supervision section).

\section{Phase V: Peer Supervision}

Peer supervision is the fifth component in the expanded model of behavioral consultation training. Individuals who completed consultation training and participated in a field-based consultation practicum continue their training by acting in a peer supervisory capacity. Specifically, they work individually with consultant-trainees and provide feedback in regard to their consultations with teachers. In this way, peer supervisors have an additional opportunity to reflect on the role they are in the process of acquiring.

The central goal of supervision is to foster reflection on knowledge and behavior (Schon, 1987). The process is defined as a joint problemsolving effort between the supervisor and the consultant through which both parties construct goals, reflect on information and actions, and develop action plans (Argyris, Putnam, \& McLain Smith, 1985; Wasik \& Fishbein, 1982). In this regard, peer supervisors act much like consultants, helping novice consultants to organize their observations and evaluate their actions.

A supervision manual has been developed to help peer supervisors structure and anticipate the supervision process (Salmon \& Sheridan, 1987). The manual serves as a general guide from which peer supervisors may continue to experiment and construct their own personal consultation framework. The organization of the manual parallels the 
phases of consultation (i.e., school entry, problem identification, problem analysis, treatment evaluation), and addresses various issues related to these. The major purpose of the manual, however, is to offer a process for approaching consultation supervision rather than specific content.

To facilitate the supervision process, the manual contains a consistent format within each phase section. This format helps supervisors structure the manner in which they prepare for their meetings with the consultants. The format includes general goals for supervision during each consultation phase, reflective questions highlighting issues that may need to be addressed, and objectives delineating specific supervisor action plans. This process of goal setting, reflection, and action planning is the same format that the consultants use in planning and reviewing their consultation interviews. Hence, supervisors use a consistent framework from which to approach their own role as a supervisor and the consultant role.

In addition to the manual, supervisors keep journals regarding their supervision sessions and set goals for objectives that they want to achieve. They also meet as a group to share and reflect on their experience as a peer supervisor. The purpose of these tools is to provide an additional means of reflecting on the consultation process and ways of facilitating consultant learning.

As a result of their experience, peer supervisors have an opportunity to reexamine many of the classic issues and challenges in school consultation (Salmon, 1988). This reflection is particularly powerful because it occurs from a third person perspective; a more distant vantage point from which to experience and to learn about the school consultant role. As a result, peer supervisors can see more clearly the complex relationship between system factors, the teacher's beliefs, and the child's characteristics, and the implication these dimensions have for the consultant's role.

\section{FUTURE TRAINING AND RESEARCH DIRECTIONS}

Training in consultation procedural, interpersonal, and professional skills is a high priority in preparation programs. Alternative formats for providing such training are important. The behavioral consultation training model presented here is believed to be important and effective at addressing critical need areas. Future research should continue to modify and refine this program to facilitate its incorporation into 
consultation courses, general practica, internships, and related training experiences.

Research and training programs should also continue to develop alternative ways to assess student growth and skill development. A multilevel evaluation model is necessary to assess consultation training outcomes. An example of one such model is presented in Table 2. The specific objectives of each of the training components should be evaluated in terms of consultants demonstration of both knowledge and application. Specific methods and possible dependent measures are explored next. It should be noted that many of the scales and methods described are primarily clinical tools. Their functional and psychometric utility are in need of empirical test.

TABLE 2

Multilevel Evaluation Model

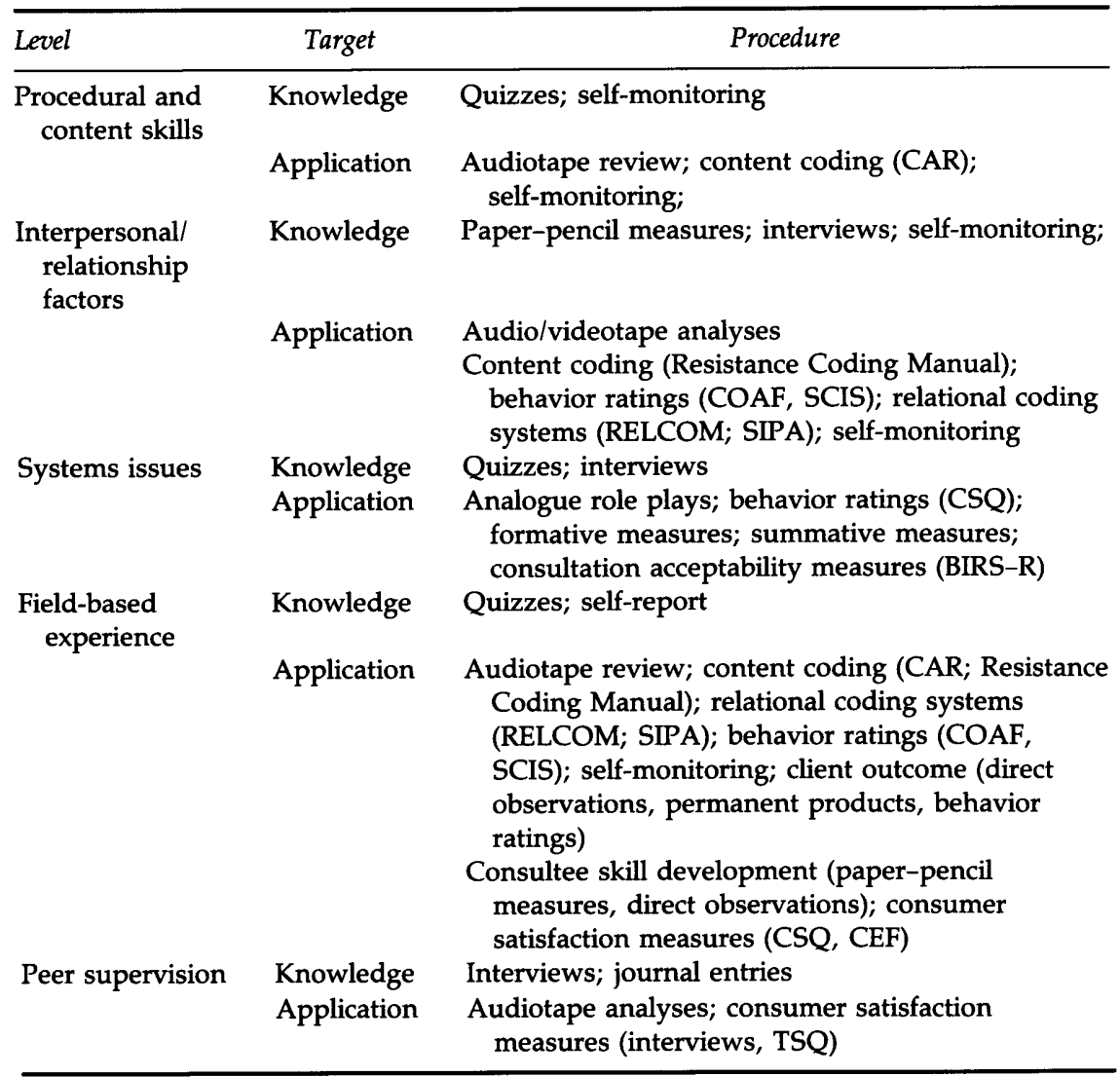




\section{Consultant Knowledge and Skills}

Knowledge. Consultant content and problem-solving knowledge can be assessed in various ways. Specifically, knowledge of the principles of behavior analysis, consultation problem-solving procedures and objectives, specific child and population characteristics, and effective interventions can be evaluated using traditional paper-and-pencil means (e.g., quizzes). Likewise, self-evaluation of content-related competence can be used to assess the match between consultants' perceptions of their own expertise and objective criterion measures.

Application. Consultants' application of knowledge and problemsolving skills may be evaluated in traditional and novel ways. For example, coding and analyses of consultation audiotapes by supervisors and trained raters may assess the degree to which specific consultation objectives were met in actual interviews (Kratochwill et al., 1991, in press; Kratochwill et al., 1989). The Consultation Analysis Record (CAR) can be used to demonstrate the relationship between consultant verbal behaviors and important consultation outcomes. This system allows classification of verbal exchanges between consultants and consultees in terms of their (a) source, (b) content, (c) process, and (d) control. It has been used in behavioral consultation training research (Kratochwill et al., in press; Kratochwill et al., 1989) to evaluate systematically the application of novice consultants' procedural and verbalization skills.

Content information (i.e., "expertise") provided by the consultant in actual cases also can be quantified and evaluated through various coding systems to provide an index of knowledge application. Likewise, consultant-trainees may conduct self-evaluations by monitoring their own performance, identifying knowledge and skill strengths and deficits, and developing behavioral goals for future consultation interactions. In this way, future research can investigate the emerging relationships between consultants' knowledge base and skills applicable in consultation interviews.

\section{Interpersonal/Relationship Factors}

Knowledge. Evaluation of consultants' knowledge in regard to the interpersonal/relationship domain should encompass both consultee and consultant variables. For example, consultants' understanding of consultee characteristics (i.e., beliefs, practices, and values) and their potential impact on consultation interactions and outcome should be assessed. Likewise, consultants' recognition of personal characteristics and the manner in which they interact with and influence the consul- 
tation process should be investigated. These variables can be evaluated through paper-and-pencil measures, semi-structured interviews, and journal entries.

Application. A variety of methods can be used to evaluate the application of consultant-trainees' interpersonal and relationship skills. Audio- and videotape analyses provide permanent products of consultation interactions, and various coding systems can be used to evaluate interpersonal skills and relational communication patterns as they relate to training objectives and their application in a specific consultation relationship. $^{2}$

An example of a content coding system applicable to interpersonal factors in consultation is the Resistance Coding Manual (Forgatch \& Chamberlin, 1982). This system represents a systematic and empirical method for defining and coding eight categories of consultant behaviors and nine categories of client behaviors. Although it was designed originally to analyze verbal interactions between a therapist and a family, it can be extended to consultation interactions to investigate the relationship between certain categories of consultant-trainee behaviors and specific consultee responses.

Numerous rating scales also have been developed to evaluate discrete interpersonal skills. Examples of such scales include the Consultant Observational Assessment Form (COAF; Curtis \& T. Anderson, 1975) and the Scale of Consultant Interpersonal Skills (SCIS; Sheridan, 1990a). These scales define and assess a number of important interviewing skills, such as the use of open questions, empathy, and attending behaviors. They can be completed by supervisors or trained raters to document the use and function of discrete interpersonal skills. Self-monitoring also can be incorporated to promote consultants' evaluations of their own interpersonal behaviors.

Along with the evaluation of discrete interpersonal behaviors, consultation relationships must be evaluated. For example, verbal interactions between the consultant and consultee, stylistic and communicative patterns shared among participants, and degree of relational control within the interview may be evaluated. Various relational communication control coding systems are available to analyze interpersonal communication and process variables. Examples include the Relational Communication Coding System (RELCOM; Rogers \& Farace, 1975) and Social Information Processing Analysis (SIPA; Fisher, Drecksel, \&

\footnotetext{
${ }^{2}$ It is beyond the scope of this article to review all of the verbal interaction coding schemes available. Interested readers are referred to a comprehensive review by Witt (1990).
} 
Werbel, 1979). Although such systems have been used in previous consultation research (Erchul, 1987; Erchul \& Chewning, 1990), similar analyses should be conducted with novice interviewers specifically to determine the degree to which they incorporate relationship training objectives into their consultation interactions.

\section{Systems Issues}

Knowledge. Few evaluative outcome measures currently are available to target consultants' systems knowledge. Nevertheless, consultant understanding of systems issues are important to investigate in training programs. Generally speaking, knowledge of these issues can be assessed through paper-and-pencil evaluation procedures (e.g., quizzes) or semi-structured interviews. For example, case scenarios or hypothetical situations can be presented to consultant-trainees with the objective of identifying various systemic factors that impact a given case.

Application. Application of systems knowledge can be evaluated in a number of ways, such as through analogue role plays and behavioral ratings. Specifically, hypothetical situations can be used to illustrate complex systems issues, and consultant-trainees can be instructed to role play potential behavioral reactions and likely outcomes. To use such methods, specific criterion objectives should be established, and consultants' performances evaluated against these behavioral measures.

Behavioral ratings by individuals within the system (e.g., teacherconsultees, school principals) provide another form of evaluation at the systems-application level. For example, the Consultation Services Questionnaire (CSQ; Zins, 1981) is a 26-item rating scale completed by consultees which contains items tapping perceptions of the degree to which consultants understand important systems issues. Examples of questions include "understands classroom and educational issues;" "fit into my school environment;" and "helped identify useful resources." However, this scale was designed primarily to evaluate consultee satisfaction and is limited in its ability to address complex systems issues adequately. There is a need to develop and validate evaluative methods that tap systems knowledge and its impact on consultation services with greater breadth and accuracy.

The impact of consultation services at the broader organizational level is an important indirect measure of training outcome worthy of investigation. At this level, formative and summative methods provide informative indices. For example, the use of consultation services and impact on service-delivery patterns are viable outcome measures. Cases referred for special education evaluation, time spent in consultation 
interactions, and interventions implemented in classroom settings can be quantified and evaluated for summative outcome purposes. Likewise, acceptability of consultation services within the system can be assessed through checklists and rating scales. The Behavior Intervention Rating Scale (BIRS; Elliott \& Von Brock Treuting, 1991; Von Brock \& Elliott, 1987) is a 24-item, factor-analyzed scale which assesses acceptability of various behavioral interventions. A modification of the BIRS has been used in previous research to assess acceptability of consultation services as provided by consultant-trainees (Sheridan, in press).

\section{Field-Based Experience}

Knowledge. The assessment of novice consultants understanding of consultation procedures, relationship factors, and systems issues ideally is evaluated throughout prior phases of training. At the point of application, their recognition of entry issues become particularly important to evaluate. Consultant knowledge of applied consultation and entry issues can be assessed through conventional formats, including quizzes and self-report. For example, readings can be assigned and trainees can be responsible for demonstrating mastery of the content through competency-based paper-and-pencil measures.

Application. In field-based experience, consultant skills are evaluated in the context of an actual consultation case. Consultants' abilities to apply their skills in practice can be assessed through the use of instruments used throughout training (e.g., audiotape analysis, content and relational coding, self-monitoring). Furthermore, their impact on consumers (i.e., clients and consultees) is essential to evaluate. In this regard, client outcome can be assessed through direct observations, permanent products, behavioral checklists, and self-reports. Change in the consultee as a function of consultant knowledge and skill can also be evaluated in various ways. For example, paper-and-pencil instruments can be used to assess a consultee's knowledge base. Direct observations can be conducted to evaluate consultee skills in implementing behavioral interventions and the degree to which consultees modify existing instructional practices or environmental contingencies. Finally, consultee self-monitoring involving both discrete behaviors and conceptualization of consultation cases can be incorporated into a total evaluation package.

Along with direct impact on consumers of consultation services, perceptions of consultees are important to assess in field-based experiences. Consumer satisfaction measures can provide information on consultee reactions to consultants' performances in actual cases. The 
Consultation Services Questionnaire (CSQ; Zins, 1981) is a 26-item scale assessing consultees' satisfaction with consultation services, perceived effectiveness of the consultant, and benefits of the model. Similarly, the Consultant Evaluation Form (CEF; Erchul, 1987) is a 12-item scale designed to measure consultee perceptions of consultant effectiveness.

\section{Peer Supervision}

Knowledge. Supervision in the expanded training model is conceptualized as a natural extension of consultation training, with previous trainees serving as peer supervisors. The knowledge base and skill level of peer supervisors in regard to the consultation process are expected to develop continuously as a function of their on-going experiences with the model. Unfortunately, the evaluation of supervision processes is still in its infant stages, and the identification of supervisor behaviors critical to consultant growth are unclear. Supervisor knowledge and skill can be evaluated in a variety of ways. Semi-structured interviews can be conducted to evaluate changes in peer supervisors' knowledge organization. Similarly, content analyses of on-going supervision journal recordings can provide documentation of peer supervisors' perceptions of salient case issues and problem-solving thought processes.

Application. Application and outcome of peer supervisors' knowledge and skills can be evaluated through audiotape analyses and consultant feedback mechanisms. Supervision sessions can be audiotaped, transcribed, and analyzed using methods similar to those used in consultant-consultee interactions. Specific content to be evaluated may include peer supervisors' statements regarding content issues, interpersonal factors, and systems variables within consultation cases. Analyses of supervisor behaviors, their relationship to consultant skill development, and their ultimate impact on consultees and clients may then be possible.

Along with specific behavioral analyses, the application of peer supervision practices should be evaluated in regard to their impact on consumers (i.e., supervisees). In this regard, consultant perceptions of training and supervision should be assessed. Semi-structured interviews and structured rating scales can be used to evaluate perceived benefits of training and supervision. For example, the Training Satisfaction Questionnaire (TSQ; Sheridan, 1990b) is a 21-item Likert scale which measures satisfaction with general training procedures and specific training components, including supervision and performance feedback. 


\section{CONCLUSIONS}

In this article, a conceptual model for behavioral consultation training was presented. The model is presented within the context of an evolution of behavioral consultation training, and potential outcome measures for various training components are suggested. As an evolutionary process, continuous modifications and refinements are necessary. For example, revisions have already been made in Phase II of training to elicit greater consultant participation and involvement using several instructional strategies such as guided readings, discussion questions, a relationship skills seminar, modeling, and role-play experiences. Likewise, a mentorship supervision model has been incorporated and field tested (Salmon \& Fenning, 1992).

Like consultation practice, the expanded consultation training model is flexible and dynamic. It does not propose to address the multitude of issues that will likely face novice consultants in all field-based situations. Rather, it equips trainees with a breadth of knowledge and experience on which to rely as they face complex and divergent consultation cases. Given individual training needs, the model can be embellished with additional content, process, or experiential components. Throughout the training process, however, it is critical that alternatives be explored in the conceptualization and evaluation of consultant competence.

\section{ACKNOWLEDGMENTS}

The conceptual model of training reported in this article was developed as part of a grant funded by the United States Department of Education, Office of Special Education and Rehabilitative Services, awarded to the third author through the Wisconsin Center for Education Research, School of Education, University of Wisconsin-Madison. The opinions expressed in this article are those of the authors and do not necessarily reflect the views of the U.S. Department of Education or the Wisconsin Center for Education Research.

We express our sincere appreciation to the staff of the Wisconsin Center for Education Research for their assistance with the project. Special appreciation is also extended to the graduate students who served as consultants, the teachers who served as consultees, and the students who received services. 


\section{REFERENCES}

Alpert, J. L., \& Yammer, M. D. (1983). Research in school consultation: A content analysis of selected journals. Professional Psychology: Research and Practice, 14, 604-612.

Anderson, C. (1983). An ecological developmental model for a family orientation in school psychology. Journal of School Psychology, 21, 179-189.

Anderson, T. K., Kratochwill, T. R., \& Bergan, J. R. (1986). Training teachers in the classroom application of behavioral modification techniques. Journal of School Psychol$o g y, 24,229-241$.

Apter, S. J. (1982). Troubled children/troubled systems. Elmsford, NY: Pergamon.

Apter, S. J., \& Conoley, J. C. (1984). Childhood behavior disorders and emotional disturbance. Englewood Cliffs, NJ: Prentice-Hall.

Argyris, C., Putnam, R., \& McLain Smith, D. (1985). Action science. San Francisco: Jossey-Bass.

Argyris, C., \& Schon, D. A. (1974). Theory in practice: Increasing professional effectiveness. San Francisco: Jossey-Bass.

Bergan, J. R. (1977). Behavioral consultation. Columbus, OH: Merrill.

Bergan, J. R., \& Kratochwill, T. R. (1990). Behavioral consultation and therapy. New York: Plenum.

Bergan, J. R., \& Tombari, M. L. (1975). The analysis of verbal interactions occurring during consultation. Journal of School Psychology, 14, 3-14.

Bergan, J. R., \& Tombari, M. L. (1976). Consultant skill and efficiency and the implementation of outcomes of consultation. Journal of School Psychology, 14, 3-14.

Brown, D. K., Kratochwill, T. R., \& Bergan, J. R. (1982). Training interview skills for problem identification: An analogue study. Behavioral Assessment, 4, 63-73.

Cantor, N., \& Kihlstrom, J. (1987). Personality and social intelligence. Englewood Cliffs, NJ: Prentice-Hall.

Carrington Rotto, P. (1988, April). Interpersonal and relationship considerations in behavioral consultation training. In T. R. Kratochwill (Chair), Future directions in behavioral consultation: An expanded training model. Symposium conducted at the meeting of the National Association of School Psychologists, Chicago.

Carrington Rotto, P., Sheridan, S. M., \& Salmon, D. (1987). Interpersonal considerations in the consultative relationship. Unpublished manual, University of Wisconsin-Madison, Wisconsin Center for Educational Research.

Carver, C. S., \& Scheier, M. F. (1982). Control theory: A useful conceptual framework for personality-Social, clinical, and health psychology. Psychological Bulletin, 92, 111-135.

Conoley, J. C., \& Conoley, C. W. (1982). School consultation: A guide to practice and training, New York: Pergamon.

Cormier, W. H., \& Cormier, L. S. (1985). Interviewing strategies for helpers: Fundamental skills and cognitive behavioral interventions. Monterey, CA: Brooks/Cole.

Curtis, M. J., \& Anderson, T. (1975). Consultant Observational Assessment Form (COAF). Cincinnati, $\mathrm{OH}$ : Department of School Psychology and Counseling, University of Cincinnati.

Curtis, M. J., \& Meyers, J. (1988). Consultation: A foundation for alternative services in the schools. In J. L. Graden, J. E. Zins, \& M. J. Curtis (Eds.), Alternative educational delivery systems: Enhancing options for all students (pp. 35-48). Washington, DC: National Association of School Psychologists.

Egan, G. (1986). The skilled helper: A systematic approach to effective helping. Monterey, CA: Brooks/Cole.

Elliott, S. N., \& Von Brock Treuting, M. (1991). The Behavior Intervention Rating Scale: 
Development and validation of a pretreatment acceptability and effectiveness measure. Journal of School Psychology, 29, 43-51.

Erchul, W. P. (1987). A relational communication analysis of control in school consultation. Professional School Psychology, 2, 113-124.

Erchul, W. P., \& Chewning, T. G. (1990). Behavioral consultation from a request centered relational communication perspective. School Psychology Quarterly, 5, 1-20.

Fine, M. J. (1990). Facilitating home-school relationships: A family-oriented approach to collaborative consultation. Journal of Educational and Psychological Consultation, 1, 169-187.

Fine, M. J., Grantham, V. L., \& Wright, J. G. (1979). Personal variables that facilitate or impede consultation. Psychology in the Schools, 16, 533-539.

Fisher, B. A., Drecksel, G. L., \& Werbel, W. S. (1979). Social Information Processing Analysis (SIPA): Coding ongoing human communication. Small Group Behavior, 10, 3-21.

Forgatch, M. S., \& Chamberlin, P. (1982). Resistance coding manual. Unpublished instrument and technical report, Oregon Social Learning Center, Eugene.

Idol, L., \& West, J. F. (1987). Consultation in special education (Part II): Training and practice. Journal of Learning Disabilities, 20, 476-497.

Kelly, G. (1955). The psychology of personal constructs (Vol 1). New York: Norton.

Kratochwill, T. R., \& Bergan, J. R. (1978). Training school psychologists: Some perspectives on a competency-based behavioral consultation model. Professional Psychology, 9 , 71-82.

Kratochwill, T. R., \& Bergan, J. R. (1990). Behavioral consultation in applied settings: An individual guide. New York: Plenum.

Kratochwill, T. R., Elliott, S. N., \& Carrington Rotto, P. (1990). Best practices in behavioral consultation. In A. Thomas \& J. Grimes (Eds.), Best practices in school psychology-II (pp. 147-170). Washington DC: National Association of School Psychology.

Kratochwill, T. R., Sheridan, S. M., Carrington Rotto, P., \& Salmon, D. (1991). Preparation of school psychologists to serve as consultants for teachers of emotionally disturbed children. School Psychology Review, 20, 530-550.

Kratochwill, T. R., Sheridan, S. M., Carrington Rotto, P., \& Salmon, D. (in press). Preparation of school psychologists in behavioral consultation service delivery: Practical, theoretical, and research considerations. In T. R. Kratochwill, S. N. Elliott, \& M. Gettinger (Eds.), Advances in school psychology (Vol. VIII). Hillsdale, NJ: Lawrence Erlbaum Associates, Inc.

Kratochwill, T. R., Van Someren, K. R., \& Sheridan, S. M. (1989). Training behavioral consultants: A competency-based model to teach interview skills. Professional School Psychology, 4, 41-58.

Meyers, J., Wurtz, R., \& Flanagan, D. (1981). A national survey investigating consultation training occurring in school psychology programs. Psychology in the Schools, 18, 297-302.

Morris, R. J., \& Nicholson, J. (in press). The therapeutic relationship in child and adolescent psychotherapy: Research issues and trends. In T. R. Kratochwill \& R. J. Morris (Eds.), Handbook of psychotherapy with children and adolescents. New York: Pergamon.

Petrie, P., Brown, K. D., Piersel, W. C., Frinfrock, S. R., Schelble, M., Leblanc, C. P., \& Kratochwill, T. R. (1980). The school psychologist as behavioral ecologist. Journal of School Psychology, 18, 222-233.

Phillips, V., \& McCullough, L. (1990). Consultation-based programming: Instituting the collaborative ethic in schools. Exceptional Children, 56, 291-304.

Pray, B., Kramer, J. J., \& Lindskog, R. (1986). Assessment and treatment of tic behavior: A review and case study. School Psychology Review, 15, 418-429. 
Rogers, L. E., \& Farace, R. V. (1975). Analysis of relational communication in dyads: New measurement procedures. Human Communication Research, 1, 222-239.

Rosenfield, S. (1985). Teacher acceptance of behavioral principles: An issue of values. Teacher Education and Special Education, 8, 153-137.

Salmon, D. (April, 1988). Peer supervision in school consultation: Goals, reflection, and action. In T. R. Kratochwill (Chair), Future directions in behavioral consultation: An expanded training model. Symposium presented at the Annual meeting of the National Association of School Psychologists, Chicago.

Salmon, D., \& Fenning, P. (1992). Developing personal theories of practice: A cognitive approach to mentorship in school consultation. Manuscript submitted for publication.

Salmon, D., \& Lehrer, R. (1989). School consultants' implicit theories of action. Professional School Psychology, 4, 173-187.

Salmon, D., \& Lehrer, R. (1991). Experience and problem representation in school consultation: Exploring the implicit theories of school psychology trainers and students. School Psychology Quarterly, 6, 112-130.

Salmon, D., \& Sheridan, S. M. (1987). Consultation supervision: Goals, reflection, and action. Unpublished manual, University of Wisconsin-Madison, Wisconsin Center for Education Research.

Schon, D. A. (1987). Educating the reflective practitioner. San Francisco: Jossey-Bass.

Sheridan, S. M. (1988, April). A conceptual model for the expansion of behavioral consultation training. In T. R. Kratochwill (Chair), Future directions in behavioral consultation: An expanded training model. Symposium conducted at the meeting of the National Association of School Psychologists, Chicago.

Sheridan, S. M. (1990a). The Scale of Consultant Interpersonal Skills (SCIS). Unpublished scale, University of Utah, Salt Lake City.

Sheridan, S. M. (1990b). The Training Satisfaction Questionnaire (TSQ). Unpublished scale, University of Utah, Salt Lake City.

Sheridan, S. M. (in press). A field-based model to train behavioral consultants. School Psychology Quarterly.

Sheridan, S. M., Kratochwill, T. R., \& Elliott, S. N. (1990). Behavioral consultation with parents and teachers: Delivering treatment for socially withdrawn children. School Psychology Review, 19, 33-52.

Smith, D. K. (1984). Practicing school psychologists: Their characteristics, activities, and populations served. Professional Psychology: Research and Practice, 15, 798-810.

Von Brock, M., \& Elliott, S. N. (1987). The influence of treatment effectiveness information on the acceptability of classroom interventions. Journal of School Psychology, 25, 131-144.

Wasik, B. H., \& Fishbein, J. E. (1982). Problem solving: A model for supervision in professional psychology. Professional Psychology, 13, 559-564.

West, J. F., \& Cannon, G. S. (1988). Essential collaborative consultation competencies for regular and special educators. Journal of Learning Disabilities, 21, 56-63.

Witt, J. C. (1990). Face-to-face verbal interaction in school-based consultation: A review of the literature. School Psychology Quarterly, 5, 199-210.

Witt, J. C., \& Martens, B. K. (1988). Problems with problem-solving consultation: A re-analysis of assumptions, methods, and goals. School Psychology Review, 17, 211-226.

Zins, J. E. (1981). Using data-based evaluation in developing school consultation services. In M. J. Curtis \& J. E. Zins (Eds.), The theory and practice of school consultation (pp. 261-268). Springfield, IL: Thomas.

Zins, J. E., Curtis, M. J., Graden, J. L., \& Ponti, C. R. (1988). Helping students succeed in the regular classroom. San Francisco: Jossey-Bass. 